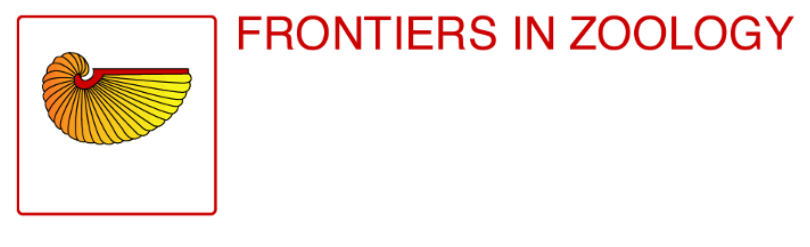

Easier detection of invertebrate "identification-key characters" with light of different wavelengths

Koken and Grall 


\title{
Easier detection of invertebrate "identification-key characters" with light of different wavelengths
}

\author{
Marcel HM Koken ${ }^{1 *}$ and Jacques Grall ${ }^{2}$
}

\begin{abstract}
The marine $\alpha$-taxonomist often encounters two problems. Firstly, the "environmental dirt" that is frequently present on the specimens and secondly the difficulty in distinguishing key-features due to the uniform colours which fixed animals often adopt.

Here we show that illuminating animals with deep-blue or ultraviolet light instead of the normal white-light abrogates both difficulties; dirt disappears and important details become clearly visible. This light regime has also two other advantages. It allows easy detection of very small, normally invisible, animals (0.1 $\mu \mathrm{m}$ range). And as these light wavelengths can induce fluorescence, new identification markers may be discovered by this approach.
\end{abstract}

Keywords: fluorescent colours, light emission, determination, cryptic species, dimorphism, pattern UV light, deepblue light, autofluorescence

\section{Introduction}

When trying to identify small marine animals the $\alpha$-taxonomist looks for features that objectively distinguish one species from another, and often he encounters two problems. Firstly, the "dirt" omnipresent in the marine environment sticks onto the specimens thereby often masking hairs, chaetae, bristles, spicules, plates, and the many other features, which require to be observed. Secondly, animals that are fixed in formalin or alcohol show a rather uniform colour (for some this is also true in their native state). Both problems make identification very time consuming and if these could be avoided determination would be easier and quicker for both taxonomists and routine observers. Here we show that illumination with deep blue or UV light completely eliminates above problems.

\section{Results}

We use a Zeiss LUMAR dissecting microscope to screen for fluorescent patterns on marine animals, to decipher potential UV light-induced behavioural signs [1-4] and to identify sources for the isolation of new fluorescent proteins, which may lead to new in situ imaging tools [5]. During these screens it became rapidly clear that

\footnotetext{
* Correspondence: koken@infobiogen.fr

'CNRS, Castel Nevez 29830 Ploudalmezeau, France

Full list of author information is available at the end of the article
}

the use of different light colours has four advantages for the taxonomist:

\section{Dirt removal}

Figure 1 shows that the small amphipod, Gammarus salina (Figure 1A, left) and the small crab, Macropodia linaresi (Figure 1B, left) are both covered with "dirt" which is clearly visible when exposed to normal light. Note how difficult it is to count the hairs on the crab or to see the hairs or the form of the chitin plates on the amphipod's body. Illumination with UV or with deep blue light results in an "optical" removal of the dirt (Figure $1 \mathrm{~A}, \mathrm{~B}, \mathrm{C}$ or $\mathrm{E}$, UV panels).

\section{Easier "identification-marker" visualisation}

UV illumination has a second positive effect as it makes plates and hairs on the exoskeleton become more clearly visible (Figure 1A, B, D, E). The animal's exoskeleton seems to "conduct the light", perhaps in a similar way to glass fibres. Note that green light failed to make the exoskeleton "light up", and that in that case dirt continued to remain visible (Figure 1E (right panel)).

As well as in crustaceans, illumination with UV (or deep-blue) light facilitates or ameliorates observation in other animal groups, as is illustrated by worm chaetae (Figure 1D) or by the clearly visible operculum on the bryozoan, Membranipora membranacea (Figure 1C).

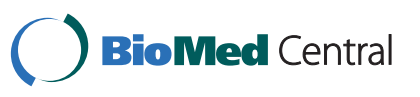

(c) 2011 Koken and Grall; licensee BioMed Central Ltd. This is an Open Access article distributed under the terms of the Creative Commons Attribution License (http://creativecommons.org/licenses/by/2.0), which permits unrestricted use, distribution, and reproduction in any medium, provided the original work is properly cited. 


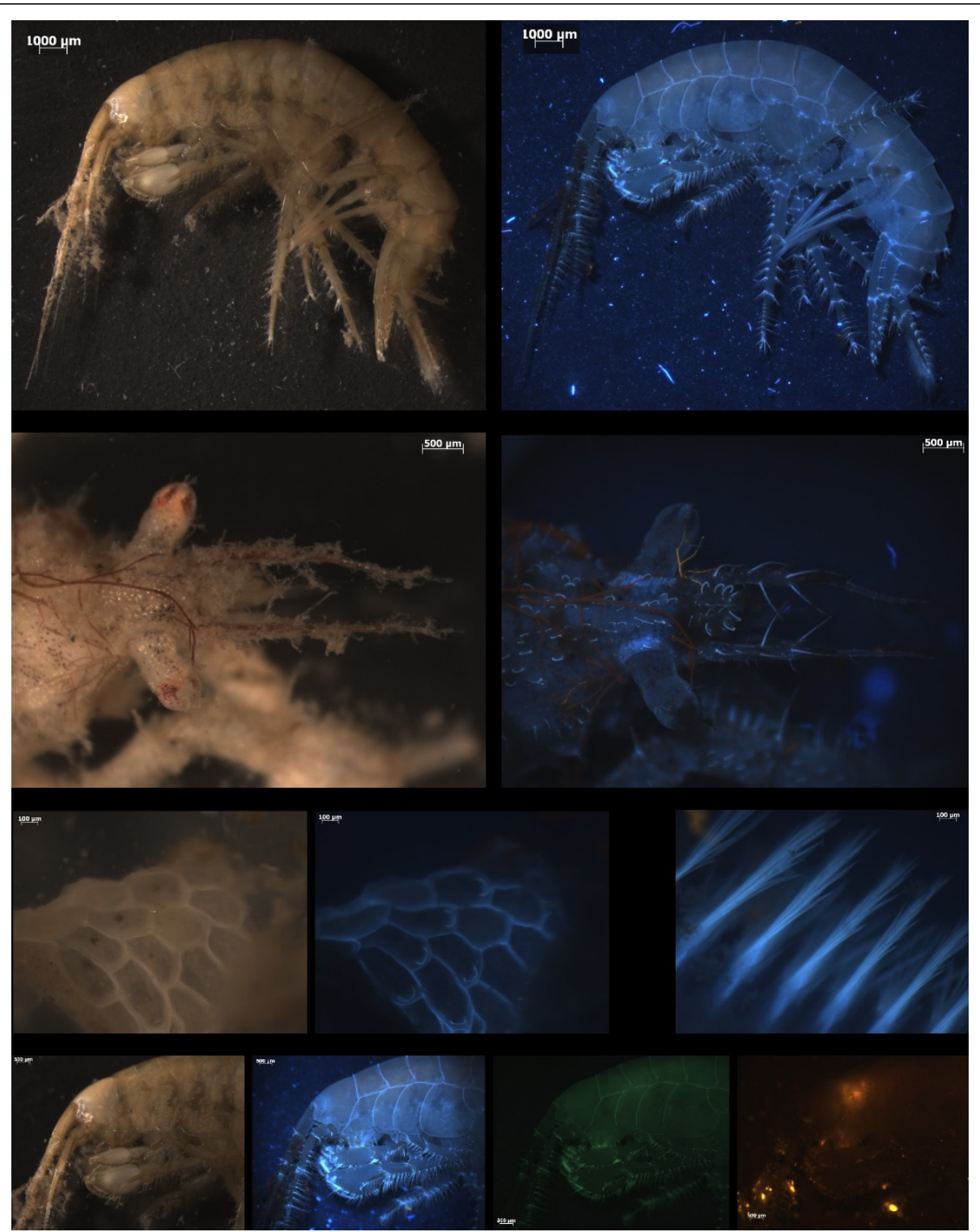

Figure 1 Use of different light colours permits easier "identification-marker" visualization and "removes dirt". A. Unfixed Gamarus salinus (Spooner, 1947). Left: "white light", Right: UV light. B. Unfixed Macropodia linaresi (Forest \& Alvarez, 1964). Left: "white light" Right: UV light. C. Unfixed Membranipora membranacea (Lineaus, 1767) Left: "white light"; Middle: UV light. D. Chaetae of a polychaete under UV light. E. Illumination with different light colors of Gamarus salinus. Left panel: white light. Left-middle panel: UV light. Right-middle panel: Blue light. Right panel: Green light.

Both, "dirt removal" and "light conveyance" work well on fresh, frozen (but subsequently thawed), ethanol- or buffered-formalin-fixed specimens (not shown).

\section{Detection of "invisible" animals}

During a routine fluorescence screen, a small brittlestar was inspected under UV light (Figure 2A), and a tiny $(200 \mu \mathrm{m})$ mite was caught walking over the arms of the echinoderm (Figure 2A (arrow), Figure 2B).

Whereas UV light allowed easy detection of this mite through the "light conveyance phenomenon" (Figure
2D), the animal was invisible without UV illumination; only its brown eyes could be seen (Figure 2C, arrow) if one knew where to look.

\section{Fluorescent identification-markers}

Applying different wavelength light/colours has another advantage over the use of white-light as it can induce fluorescence colours on the specimen. Many marine species show specific fluorescent patterns. For instance, in Figure 3 the fluorescence pattern of a scale (elytrum) of the polynoid worm, Harmothoe impar shows that a 

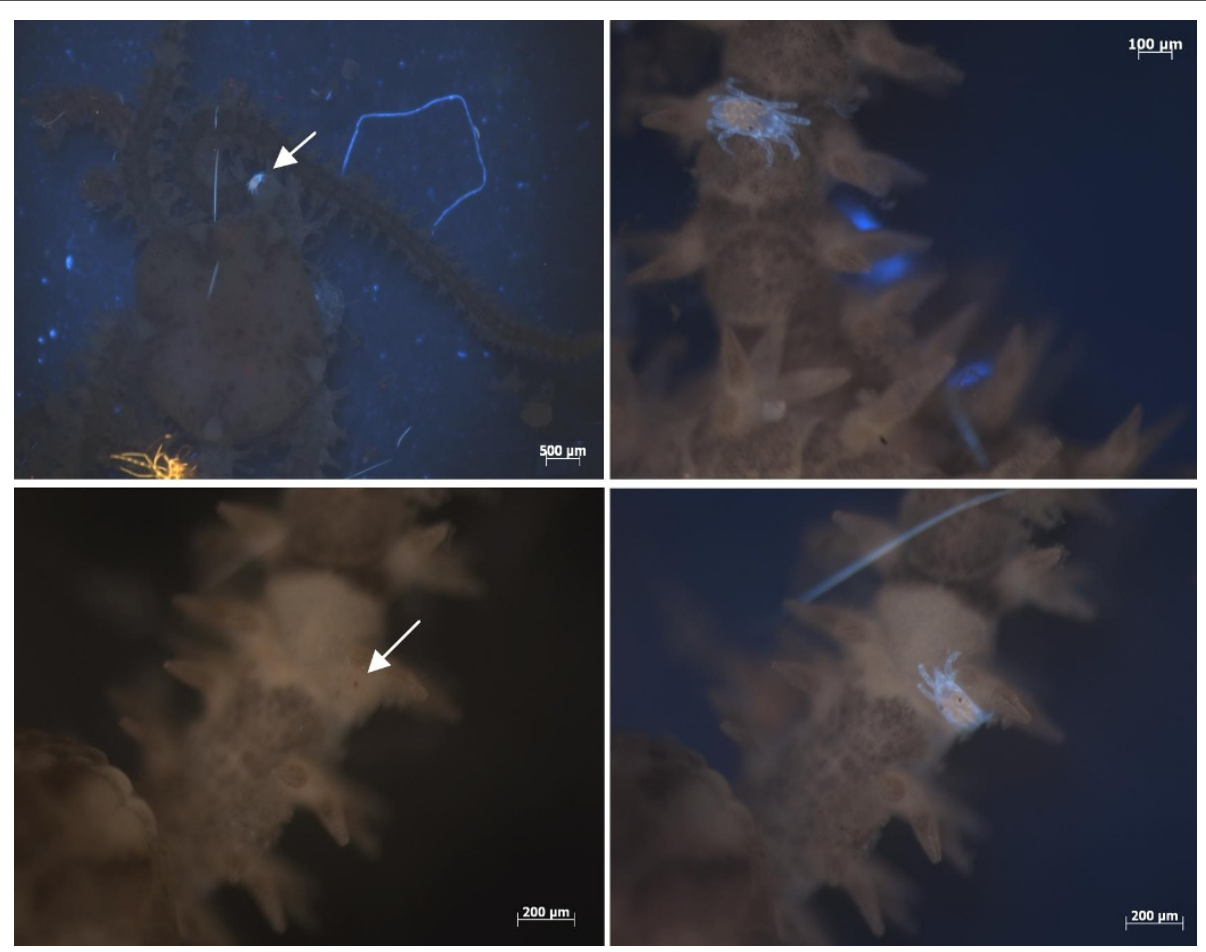

Figure 2 Different light colours allow visualization of otherwise "invisible" animals. A (Upper left panel). Illumination of an unfixed brittlestar with UV light. Please note the small mite indicated by the arrow. B (Upper right panel): Zoom of A. C (Lower left panel) and D (lower right panel). An arm of the brittlestar under white (left) and UV light (right). Please note, the two brown eyes (arrow), the only visible part of the mite under white light.

lot of additional information can be obtained which is not visible under white-light illumination. Unfortunately, in most cases this works only on fresh or frozen (and thawed) samples. Fixation rapidly destroys most of the fluors that we have encountered thus far.

\section{Discussion}

We show here that changing the classical white-light illumination for a deep-blue or UV light source has

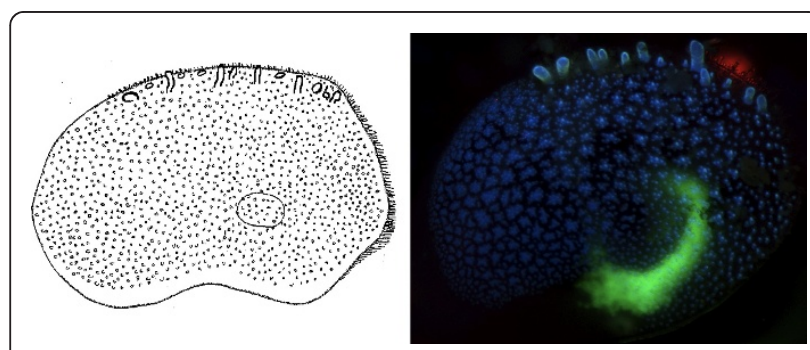

Figure 3 Different light colours may provide additional identification-markers though the induction of fluorescent patterns. Left panel. Line drawing of a scale from Harmothoe impar (Johnston, 1839). Right panel. Superposition of UV light and deepblue light exposure of a scale of Harmothoe impar. Note, the blue and green fluorescence that is induced, and the composite form of the "spots" which is invisible with "white light". several advantages. The "dirt removal" combined with the "light conveyance" phenomenon speeds up and eases significantly the visualisation of identification markers. It may be possible that in certain cases this approach would avoid the need for staining, or even the use of immunological approaches that are often necessary for revealing certain details. And as even the tiniest of hairs "light up" it may be that scanning electron microscopy could prove sometimes unnecessary for identification.

"Dirt" is generally not a problem when examining terrestrial animals, but the "light conveyance phenomenon" is also a great help for revealing fine details on the bodies of land invertebrates (data not shown).

An additional advantage of both phenomena is that they will facilitate the scientific drawing process. For instance, the picture of Figure 1B (right panel) can very easily be transformed into a simple line drawing with Photoshop or an equivalent program.

To the best of our knowledge both the "dirt removal" and the "light conveyance" phenomena were never reported before. Both are extremely convenient when studying invertebrates as identification markers are much easier visualized with only a change of light colour. The same "light conveyance" phenomenon 
facilitates also the visualization of small organisms that under normal light regimes remain invisible. We cannot exclude that what we call "light conveyance phenomenon" is in reality the fluorescence of a resistant fluor that is very commonly found in all groups we investigated thus far, and which has a very large excitation and emission spectrum. Although we cannot be sure about the physical explanation of the phenomenon, its usefulness for the taxonomist remains without doubt.

The use of blue light-elicited autofluorescence in medicine started only a few years ago and was found to be very helpful for distinguishing between normal and abnormal or cancerous tissues [6-9]. Autofluorescence depends on the presence of endogenous fluors that are of changing type and which differ in concentrations between various tissues $[6,8]$. These differences allow therefore visualizing tissue morphological or physiological changes or tissue invasion [6]. By these means the MD can repair or remove the "abnormal" tissues while leaving the healthy tissues unharmed.

In a few reports, autofluorescence is also used to distinguish between closely resembling spores [10-12] or pollen [13]. It can also help by distinguishing between live and dead cells [14] or by allowing the detection of insect larvae which contaminate food [15].

In our screens we often detect specific fluorescence patterns on the animals' bodies and these may provide new identification-markers for correct or if not, easier identification.

These additional fluorescence patterns may allow distinction between similar species [16] or lead to the identification of thus far invisible sexual dimorphism or patterns that change during development.

These patterns are presently ignored by the animal taxonomist, but should not be excluded as they may represent additional valid identification markers

In conclusion, we believe that inspecting specimens with different light colours, most importantly with UV or deep blue light, will greatly facilitate the identification of specimens. Moreover, this approach has the potential to detect (sub)species, dimorphisms or developmental patterns, which under normal light regimes remain completely invisible and may be still unknown to science.

\section{Methods \\ Samples}

Animals used in this study were collected at low tide at "Melon-Porspoder" and "Le Dellec - Plouzané" (Brittany, France). Moving live animals were narcotized, mostly by immersion in a $7.5 \% \mathrm{MgCl}_{2}$ solution in seawater, or by other described methods [17]. All biological material has been collected under appropriate collection permits and approved ethics guidelines.

\section{Fixation conditions}

Animals were examined either after fixation or in native condition. Fixation was done in $70 \%$ ethanol (in seawater) for 1 hour or for 4 days, or in $7 \%$ buffered formalin (in seawater) for 1 hour or 4 days. After fixation specimens were transferred into sterile seawater for long-term storage.

\section{Microscopy}

Samples were inspected on a Zeiss LUMAR V12 dissecting microscope with a Axiocam MrC5 colour camera 5. The following excitation/emission filter sets were mounted:

- set 01 UV, Ex BP 365/12, EM LP 397 ("UV" in the figure legends).

- set 38 GFP, Ex BP 470/40, EM BP 525/50 ("blue").

- set 43 Cy3, Ex BP 545/25, EM BP 605/70 ("green").

\section{Abbreviations}

UV: ultraviolet light; MD: medical doctor.

\section{Acknowledgements}

We want to thank J. Tchoubar (Carl Zeiss S.A.S., France) for lending us a LUMAR dissecting microscope during the "Défi pour la biodiversité" in the "Golf de Morbihan" (5 to 7 june 2009, Séné, France). We also thank the two anonymous referees for their comments and suggestions that have most certainly improved our manuscript. Finally, we are grateful to the indigenous Englishman and his wife who corrected our corrupted English late into the night. This work was financed indirectly by the "Association pour la Recherche sur le Cancer" (Contract N ${ }^{\circ}$ 5907), the "Association Française contre les Myopathies" (Contract N²70), and by a "Programme de Recherche d'Intérêt Régional" of the Brittany region (Contract "BIOLUM 116").

\section{Author details}

${ }^{1}$ CNRS, Castel Nevez 29830 Ploudalmezeau, France. ${ }^{2}$ CNRS UMS3113, Observatoire IUEM, UBO, Rue Dumont d'Urville 29280 Plouzané, France.

\section{Authors' contributions}

Both authors contributed equally to this work. Both authors read and approved the final manuscript.

\section{Competing interests}

The authors declare that they have no competing interests.

Received: 25 July 2011 Accepted: 31 October 2011

Published: 31 October 2011

\section{References}

1. Siebeck UE, Parker AN, Sprenger D, Mathger LM, Wallis G: A species of reef fish that uses ultraviolet patterns for covert face recognition. Curr Biol 2010, 20:407-410.

2. Griggio $M$, Hoi H, Pilastro A: Plumage maintenance affects ultraviolet colour and female preference in the budgerigar. Behav Processes 2010, 84:739-744.

3. Mazel $\mathrm{CH}$, Cronin TW, Caldwell RL, Marshall NJ: Fluorescent Enhancement of Signaling in a Mantis Shrimp. Science 2004, 303:51.

4. Lim ML, Li D: Behavioural evidence of UV sensitivity in jumping spiders (Araneae: Salticidae). J Comp Physiol A Neuroethol Sens Neural Behav Physiol 2006, 192:871-878

5. Tsien RY: Imagining imaging's future. Nat Rev Mol Cell Biol 2003, , Suppl: SS16-21.

6. Monici M: Cell and tissue autofluorescence research and diagnostic applications. Biotechnol Annu Rev 2005, 11:227-256. 
7. Schmitz-Valckenberg S, Holz FG, Bird AC, Spaide RF: Fundus autofluorescence imaging: review and perspectives. Retina 2008, 28:385-409

8. Bottiroli G, Croce AC: Autofluorescence spectroscopy of cells and tissues as a tool for biomedical diagnosis. In Comprehensive Series in Photochemical \& Photobiological Sciences. Volume 4. Edited by: Palumbo G, Pratesi R. Lasers and Current Optical techniques in Biology; 2004:189-210.

9. DaCosta RS, Wilson BC, Marcon NE: Fluorescence and spectral imaging. ScientificWorldJournal 2007, 7:2046-2071.

10. Poulickova A, Zizka Z, Hasler P, Benada O: Zygnematalean zygospores: morphological features and use in species identification. Folia Microbiol (Praha) 2007, 52:135-145.

11. Tang YZ, Dobbs FC: Green autofluorescence in dinoflagellates, diatoms, and other microalgae and its implications for vital staining and morphological studies. Appl Environ Microbiol 2007, 73:2306-2313.

12. Sarasanandarajah S, Kunnil J, Chacko E, Bronk BV, Reinisch L: Reversible changes in fluorescence of bacterial endospores found in aerosols due to hydration/drying. J Aerosol Sci 2005, 36:689-699.

13. Mitsumoto K, Yabusaki K, Aoyagi H: Classification of pollen species using autofluorescence image analysis. J Biosci Bioeng 2009, 107:90-94.

14. Hennings L, Kaufmann Y, Griffin R, Siegel E, Novak P, Corry P, Moros EG, Shafirstein G: Dead or alive? Autofluorescence distinguishes heat-fixed from viable cells. Int J Hyperthermia 2009, 25:355-363.

15. Abels JP, Ludescher RD: Native fluorescence from juvenile stages of common food storage insects. J Agric Food Chem 2003, 51:544-549.

16. Liang $Z T$, Jiang $Z H$, Leung KS, Peng $Y$, Zhao ZZ: Distinguishing the medicinal herb Oldenlandia diffusa from similar species of the same genus using fluorescence microscopy. Microsc Res Tech 2006, 69:277-282.

17. Smaldon G, Lee EW: A synopsis of methods for the narcotisation of marine invertebrates Edinburgh: Royal Scottish Museum; 1979.

doi:10.1186/1742-9994-8-27

Cite this article as: Koken and Grall: Easier detection of invertebrate "identification-key characters" with light of different wavelengths.

Frontiers in Zoology 2011 8:27.

\section{Submit your next manuscript to BioMed Central} and take full advantage of:

- Convenient online submission

- Thorough peer review

- No space constraints or color figure charges

- Immediate publication on acceptance

- Inclusion in PubMed, CAS, Scopus and Google Scholar

- Research which is freely available for redistribution

Submit your manuscript at www.biomedcentral.com/submit
CioMed Central 